\title{
Management of Distal Femoral fractures with Locking Compression Plate- A Prospective study
}

\author{
Abhijit Maruti Kadam 1 , Sujay K Mahadik ${ }^{2}$, Sagar Rampure ${ }^{3}$, Rahil B Jiwani ${ }^{4}$ \\ ${ }_{1,2,4}$ Assistant Professor, ${ }^{3}$ Junior Resident, Department of Orthopedics, Bharati Vidyapeeth (Deemed to be University) \\ Medical College and Hospital, Sangli, Maharashtra, India
}

Background: Distal femoral fractures are one of the common type of fractures seen after motor vehicular accidents. The optimal management of these fractures requires open reduction and internal fixation by plates and screws. Various studies have shown that open reduction and internal fixation by plates and screws result in early post-operative knee mobilization which is essential for good union and better functional outcome. Aims and Objective: The current study was conducted to evaluate the results of fracture lower end of femur treated by open reduction and internal fixation using locking compression plate. Materials and Methods: This was a prospective clinical study in which the cases with fracture lower end of femur were included on the basis of a predefined inclusion and exclusion criteria. Fractures were categorised by Mullers classification. All patients were treated by distal femoral locking compression plates and screws. The cases were followed up for radiological union and functional outcome (Neer's scoring). The statistical analysis was done using SSPS 21.0 software. $P$ value less than 0.05 was taken as statistically significant. Results: Out of the 20 studied cases there were $13(65 \%)$ males and $7(35 \%)$ females with a M:F ratio of 1:0.53. Road traffic accidents were the most common cause $(75 \%)$ of distal femoral fractures. The most common type of fracture seen in studied cases was found to be Mullers C2 type of fracture (45\%) followed by Mullers C3 (20\%) and Mullers C1 (15\%). All patients were treated by open reduction and internal fixation. Mean Injury to surgery interval was found to be 4.25 days in studied cases. Postoperatively desirable knee flexion (1100) was achieved in $10(50 \%)$ cases whereas in 8 patients 910-1090knee flexion was achieved. In $2(10 \%)$ patients less than 900 knee flexion could be achieved. The functional outcome (as assessed by Neer's score) showed that Good and fair results were seen in $13(65 \%)$ and $6(30 \%)$ patients. Poor functional outcome was seen in only $1(5 \%)$ patient. Conclusion: Locking compression plate is found to have good results in patients with traumatic distal femoral fractures in terms of early mobilization and functional outcome. Particularly in intra-articular fractures it provides good angular stability by its triangular reconstruction principle.

Key words: Distal Femoral Fractures; Open Reduction and Internal Fixation; Functional Outcome; Neer's Score

\section{INTRODUCTION}

In the last few decades, rapid industrialization and the fast pace of life have brought both comforts and catastrophes like road traffic accidents and crippling many young lives. Traumatic fractures of femur and other limb injuries have become a common occurrence in modern day word. ${ }^{1}$
Non-traumatic fractures of distal femoral end is seen in elderly patients in whom these fractures may occur after trivial trauma. Fracture lower end of femur are often difficult to treat and they are associated with many complications. ${ }^{2}$

In the early 1960s, there was a great reluctance towards operative management of these fractures because of high 
incidence of infection, non-union, malunion, inadequate fixation and lack of proper instruments, implant as well as antibiotics. ${ }^{3}$ Then, the traditional management of displaced supracondylar fracture of femur was along the principle of Watson Jones \& John Charnley. This comprised of skeletal traction, manipulation of fracture and external immobilization in the form of casts and cast bracings. ${ }^{4}$ However limb deformity, shortening; knee stiffness and knee instability were common problems following skeletal traction and external immobilization. ${ }^{5}$

The trend of open reduction and internal fixation has become evident in the recent years with good results being obtained with the $\mathrm{AO}$ blade plate, dynamic condylar screw, intramedullary supracondylar and other implant system like locking compression plates. This procedure is also found to have good anatomical reduction thereby giving good functional results in traumatic as well as non-traumatic distal femoral fractures. ${ }^{6}$ Elderly patients with severe osteoporosis add further to the difficulties in management of fractures around knee which requires restoration of articular congruency for painless free movements of joint. Loss of stable fixation in osteoporotic bones is of great concern in such elderly patients. Locking compression plates with its numerous advantages is of great use in such circumstances. $^{7}$

Locking compression plate has the advantage of combination of conventional compression plating and locked plating techniques which enhances the plate osteosynthesis. Anatomically precontoured built reduces soft tissue problems and acts as internal external fixator. ${ }^{8}$ In addition, a locking compression plate has got distinct advantages of unicortical fixation and least chance of plate back out as the screw gets locked to the plate. Further, minimal soft tissue injury occurs when closed reduction is done and MIPO technique is used. ${ }^{9}$ A careful intraoperative attention must be given to restoring alignment in all planes. Restoration of medial as well as lateral column is essential to prevent complication. When properly done this technique is associated with better healing, low post-operative infection, prospect of early mobilizationand better functional outcome. Early mobilization is associated with reduced stiffness as well as decreased chances of complications such as deep vein thrombosis, muscle weakness and atrophy. With good results of locking compression plates almost all orthopaedic surgeons are of the view that almost all distal femoral fractures must be treated operatively for better functional outcome. ${ }^{10}$

The purpose of this study is to evaluate the results of fracture lower end of femur treated by open reduction and internal fixation using locking compression plate.

\section{MATERIALS AND METHODS}

This was a prospective clinical study in which the cases with fracture lower end of femur were included on the basis of a predefined inclusion and exclusion criteria. The study was conducted in the Department of Orthopaedics of a tertiary care medical college located in an urban area. In this study patients with traumatic distal femoral fractures were included on the basis of a predefined inclusion and exclusion criteria. The study was pre-approved by the ethical committee of the institution.

\section{Patients and methods}

All the fractures in this series were post-traumatic. The method used for fracture fixation was open reduction and internal fixation with locking compression plate. The follow up of patients was done at 1 month, 3 months and 12 months. No pathological fractures were included in the study. Also, supracondylar fractures in children were included. Supracondylar fractures treated conservatively and fixed with other fixation systems like AO blade plate and condylar buttress plate were not included.

\section{Patient selection}

Patients admitted to Bharati Vidyapeeth Deemed University Medical college and Hospital over a period of 2 years during May 2017 to April 2019 study period, under Department of Orthopaedics, Sangli with fracture lower end of femur.

\section{Inclusion criteria}

1. Those patients who are above the age of 18 yrs., male and female with unstable, comminuted or intraarticular fractures of distal end femur.

2. Patients willing for treatment and given informed written consent

3. All types of fracture lower end of femur (AO TYPE A, B and C) were included in this study.

4. Only closed fractures and Grade I open uncomplicated were included.

\section{Exclusion criteria}

1. Patient below 18 years

2. Compound fractures associated with vascular injuries and neurological deficits.

3. Patient not willing for treatment.

4. Pathological fractures.

5. Patients who didn't turn up for follow up.

\section{PREOPERATIVE INVESTIGATION}

All patients underwent basic investigations such as complete blood count, Blood sugar level, Renal function tests (Blood urea and serum creatinine levels), Hepatic function test, 
Blood group and Rh typing, Bleeding time, clotting time and prothrombin time. Imaging in the form was $\mathrm{X}$-ray was done in all cases. $3 \mathrm{D}$ computerised tomography was done in selected cases.

\section{Methodology}

Demographic details such as age, Sex and address was noted. Mode of trauma and Period between injury and arrival was documented. A detailed history was taken and general and systemic examination as well as local examination of the patient was done in all the cases. Thorough assessment of patient to rule out head/ chest/ abdominal/ spinal or pelvic injury was done. Musculo-skeletal examination of patient was done to rule out associated fractures. Stabilization of patient was done with intravenous fluids, oxygen and blood transfusion as an when required. Careful assessment of injured limb as regards to neurovascular status was done. Primary immobilization of involved limb in Thomas splint with a cotton pad below the distal fragment was done and the patients were then sent to Department of Radiodiagnosis for imaging. Anteroposterior and true lateral views of injured limb including complete knee joint and distal femur/proximal tibia were taken. Upper tibial skeletal pin traction with a Steinmann or Derham pin drilled under local anaesthesia followed by continuous traction given over Bohler-Braun splint for fracture lower end of femur.

\section{Implant used}

The plate and screws used were manufactured from $316 \mathrm{~L}$ stainless alloy with gun drilling technique. The locking compression plates are available from 5 holed to 12 holed with 4.5 thickness plate for lower end of femur. Anatomically precontoured plate head with soft edges were used. Locking screws were employed in the head of the plate for a secure support and the head of the locking screw was threaded to get it locked to the plate as it is tightened. LCP combi-holes in the plate shaft were used for intraoperative choice between angular stability and or compression.

\section{Surgical procedure}

Patient was placed supine on a radiolucent table with a pillow below the knee, the entire injured extremity and ipsilateral iliac crest are prepared and draped. Tourniquet was applied and inflated. Lateral incision was made parallel to the shaft of the femur, beginning at the Gerdy tubercle and extending proximally far enough to permit application. Longitudinal incision was made through the fascia lata, and extended distally into the iliotibial band. The distal part of the incision is extended through the lateral joint capsule and synovium, avoiding injury to the meniscus.

More proximally, the fascia overlying the vastus lateralis muscle incised and the muscle reflected anteriorly off the intermuscular septum and perforating vessels are identified and ligated or coagulate. Minimal Stripping of soft tissue necessary for application of the plate and reduction of the articular surface is done. Often the shaft of the femur was seen to be wedged between two condyles; if so, by applying traction to the leg with the knee flexed, wedged shaft of femur is displaced. A femoral distractor is especially useful for sustained traction. Quadriceps mechanism and the patella are reflected medially to expose the entire lower end of the femur.

To aid in reduction of the condyle, a Steinmann pin was drilled into the lateral surface of the lateral condyle, if needed, a similar pin was placed in the medial condylar fragment. Using these pins as levers, manipulation and reduction of the two major condylar fragments was done to restore the articular surface and patellofemoral groove. Two condyles were fixed together with multiple 2-mm Kirschner wires. Medial and lateral condyles together were fixed with $6.5-\mathrm{mm}$ cancellous screws directed lateral to medial, taking care not to interfere with the subsequent path of other cancellous screws of locking compression plate. Second screw was placed without a washer, slightly anterior and proximal to the first. Kirschner wires used for temporary fixation was removed.

Reduction of the fracture was assisted keeping folded pillow below the knee which prevented posterior angulation of distal fragment with manual traction. Once the fracture is reduced, supplemental locking screws were then added to create a fixed-angle construct.

\section{Follow up}

Patients were followed up at 1 month, 3 months, 6 months and 12 months. We advised partial weight bearing from 4th week and full weight bearing was allowed after radiological evidence of healing. During each follow up visit patients were assessed for functional outcome on the basis of Neer's score. Patients were also followed up for presence of complications such as Presence of Infection, Stiffness, Bone healing problems, Implants failure, Mal union and Non-union.

\section{Statistical analysis}

The data was collected in excel sheet and the statistical analysis was done using SSPS 21.0 software. P value less than 0.05 was taken as statistically significant.

\section{RESULTS}

In this study 20 patients with distal femoral fractures were included on the basis of a predefined inclusion and exclusion criteria. Out of the 20 studied cases there were 13 (65\%) males and $7(35 \%)$ females with a M:F ratio of 1:0.53 (Figure 1). 
The analysis of the cases on the basis of mechanism of injuries showed that out of 20 cases majority of the patients $(75 \%)$ had distal femoral fracture following road traffic accidents. The other causes of fractures included falls $(15 \%)$ and assault (10\%) (Figure 2).

Right side was found to be predominantly affected as compared to left side. Out of 20 cases lower end of femur fracture was seen on right side in 12 patients $(60 \%)$ whereas left side was affected in $8(40 \%)$ cases (Table 1$)$.

The analysis of cases on the basis of age and mechanism of injury showed that vehicular accidents was the most common cause of fracture in patients. While $9(45 \%)$ patients with vehicular accidents were less than 50 years and $6(30 \%)$ patients were above 50 years of age. Fall as a cause of fracture was seen in $2(10 \%)$ patients of above 50 years age group and $1(5 \%)$ patient of less than 50 years of age. There were $2(10 \%)$ patients in whom assault was the

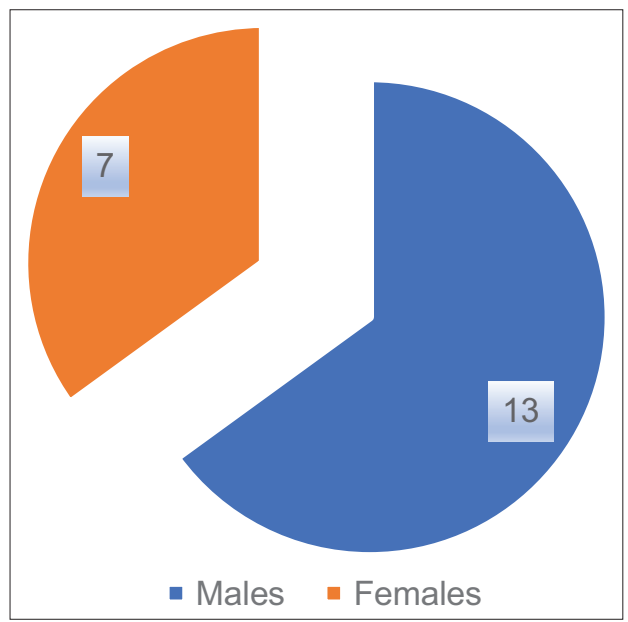

Figure 1: Gender Distribution of the studied cases.

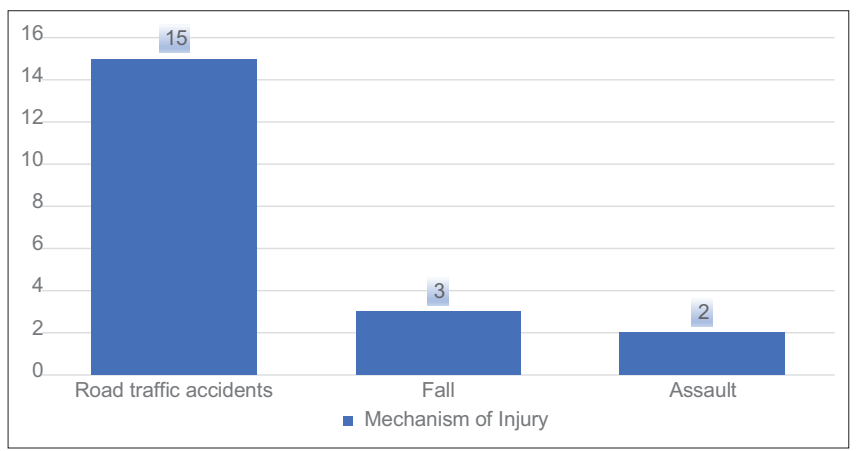

Figure 2: Mechanism of Injury in the studied cases.

Table 1: Affected side in studied cases

\begin{tabular}{lcc} 
Side affected & No of patients & Percentage \\
\hline Right & 12 & $60 \%$ \\
Left & 8 & $40 \%$ \\
Total & 20 & $100 \%$ \\
\hline
\end{tabular}

cause of fracture and both of them were below 50 years of age (Table 2).

The various types of fracture lower end of femur seen in studied cases were classified according to Mullers classification. The most common type of fracture seen in studied cases was found to be Mullers C2 type of fracture (45\%) followed by Mullers C3 (20\%) and Mullers C1 (15\%). Mullers A1 and Mullers A2 fractures were seen in $2(10 \%)$ patients each (Table 3).

Two (10\%) patients had associated injury as a consequence of trauma. Associated injuries included Musculo-skeletal and systemic injuries. One had ipsilateral distal radius fracture and one had ipsilateral patella fracture. There were no cases of any major systemic injuries (Figure 3).

Internal fixation was done only after stabilization of medical and general condition of the patients. In $9(45 \%)$ cases injury to surgery interval was 4-7 days. Whereas injury to surgery duration was 1-3 days in $8(40 \%)$ patients. In 3 (15\%) patients' surgery was done after 7 days. Mean Injury to surgery interval was found to be 4.25 days in studied cases (Table 4).

All patients were treated by open reduction and internal fixation. The shortest duration of surgery was found to be 80 minutes whereas longest surgery duration was 130 minutes. The mean surgery duration was found to be 101 minutes (Table 5).

The size of plate was selected based on the type of fracture. 5 and 6 holed plates were used more commonly for lower end of femur (Table 6).

The cases were followed up for radiological union and it was found that in $14(70 \%)$ radiological union was seen between 16-18 weeks of internal fixation. In remaining 6 cases the radiological union was achieved between 19-20 weeks. There were no cases of delayed or non-union in studied cases (Figure 4).

The analysis of the cases on the basis of time required for full weight bearing showed that in $14(70 \%)$ cases the weight bearing was achieved between 15-16 weeks. Whereas in 5 (25\%) patients the full weight bearing was achieved between 17-18 weeks. 1 patient required more than 18 weeks for achievement of full weight bearing (Table 7).

Postoperatively desirable knee flexion $\left(110^{\circ}\right)$ was achieved in $10(50 \%)$ cases whereas in 8 patients $91^{\circ}-109^{\circ}$ knee flexion was achieved. In $2(10 \%)$ patients less than $90^{\circ}$ knee flexion could be achieved. The mean knee flexion was found to be $105^{\circ}$. Knee Extensor lag was found to be $0-5^{0}$ in 11 (55\%) 
Table 2: Mechanism of fracture in studied cases

\begin{tabular}{|c|c|c|c|c|c|c|}
\hline & \multicolumn{2}{|c|}{ Vehicular Accidents } & \multicolumn{2}{|c|}{ Fall } & \multicolumn{2}{|c|}{ Assault } \\
\hline & Number & Percentage & Number & Percentage & Number & Percentage \\
\hline 50 yrs. and above & 6 & $30 \%$ & 2 & $10 \%$ & 0 & $0 \%$ \\
\hline Less than 50 yrs. & 9 & $45 \%$ & 1 & $5 \%$ & 2 & $10 \%$ \\
\hline Total & 15 & $75 \%$ & 3 & $15 \%$ & 2 & $10 \%$ \\
\hline
\end{tabular}

\begin{tabular}{lcc}
\multicolumn{3}{l}{ Table 3: Mullers classification of fracture type } \\
\hline Type of Fracture & No. of patients & Percentage \\
\hline Mullers Al & 2 & 10 \\
Hullers A2 & 2 & 10 \\
Mullers A3 & 0 & 0 \\
Mullers B1 & 0 & 0 \\
Mullers B2 & 0 & 0 \\
Mullers B3 & 0 & 0 \\
Mullers Ci & 3 & 15 \\
Mullers C2 & 9 & 45 \\
Mullers C3 & 4 & 20 \\
Total & 20 & 100 \\
\hline
\end{tabular}

Table 4: Injury- Surgery Interval in studied cases

\begin{tabular}{lcc}
\hline Injury-Surgery Interval (Days) & No. of cases & Percentage \\
\hline 1-3 Days & 8 & 40 \\
4-7 Days & 9 & 45 \\
More than 7 days & 3 & 15 \\
Total & 20 & 100 \\
\hline
\end{tabular}

\begin{tabular}{lcc}
\multicolumn{3}{l}{ Table 5: Operative Time in studied cases } \\
\hline Operative time (minutes) & No. of cases & Percentage \\
\hline$<90$ min & 6 & 30 \\
$91-120$ min & 13 & 65 \\
$>120$ min & 1 & 5 \\
Total & 20 & 100 \\
\hline
\end{tabular}

\begin{tabular}{lcc} 
Table 6: Size of plate used \\
\hline Plate size & \multicolumn{2}{c}{ Femur lower end } \\
\cline { 2 - 3 } & No. Of cases & Percentage \\
\hline $4-6$ Holed & 12 & 60 \\
$7-9$ Holed & 6 & 30 \\
$10-12$ Holed & 2 & 10 \\
Total & 20 & 100.00 \\
\hline
\end{tabular}

\begin{tabular}{lcc}
\multicolumn{3}{l}{ Table 7: Time required for full weight-bearing } \\
\hline Duration & No. of cases & Percentage \\
\hline $12-14$ weeks & 14 & 70.00 \\
$15-16$ weeks & 5 & 25.00 \\
$17-18$ weeks & 1 & 5.00 \\
$>18$ weeks & 20 & 100.00 \\
\hline
\end{tabular}

patients whereas it was found to be $6^{0}-10^{\circ}$ in $8(40 \%)$ cases. In remaining $1(5 \%)$ patient it was more than $10^{\circ}$. The mean extensor lag in our study was found to be $5.55^{\circ}$. Limb length discrepancy was seen in $3(15 \%)$ patients. Out of these 3 patients limb length discrepancy of $0.5-1 \mathrm{cms}$ and more

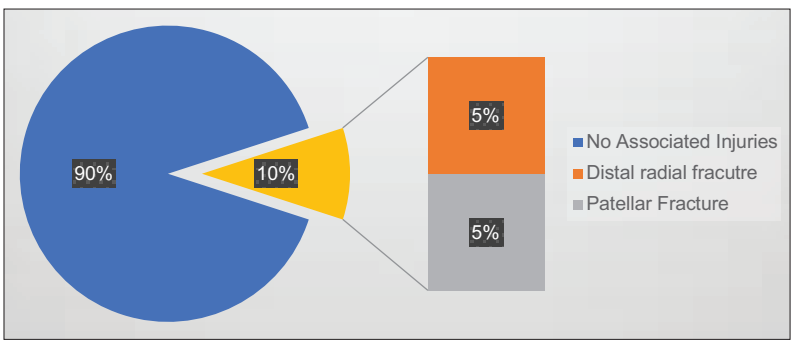

Figure 3: Associated injuries in studied cases

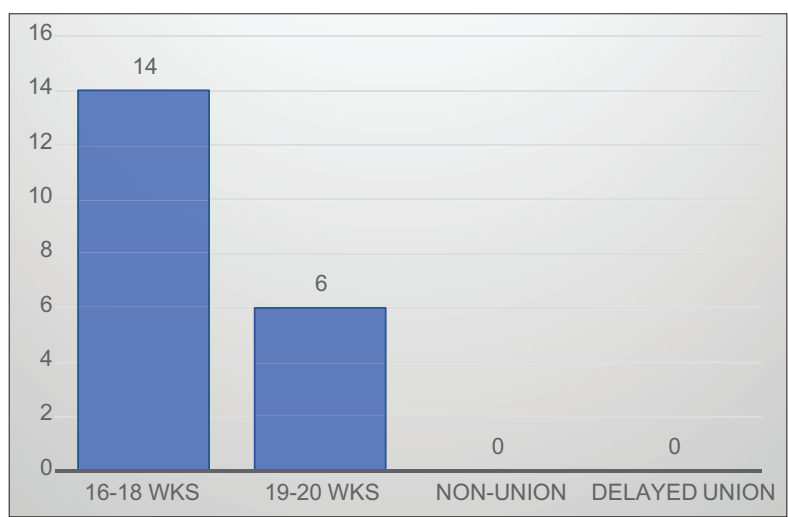

Figure 4: Achievement of radiological Union in studied cases

than $1 \mathrm{cms}$ was found in $2(10 \%)$ and $1(5 \%)$ patient. In 6 $(30 \%)$ patients malalignment of more than $5^{0}$ was found. Out of these 6 patients Varus and Valgus malalignment was seen in $3(15 \%)$ patients each. $15(75 \%)$ patients recovered completely and didn't have to change the nature of work they were doing before fracture whereas remaining 5 (25\%) persons had to change their profession. $4(20 \%)$ had to alter nature of their work whereas $1(5 \%)$ patient could only do light work. Superficial and Deep infections were seen in $2(5 \%)$ patients each. Other complications such as Nonunion, Mal union, implant failure or stress fractures were not seen in any of the cases. The functional outcome (as assessed by Neer's score) showed that Good and fair results were seen in $13(65 \%)$ and $6(30 \%)$ patients. Poor functional outcome was seen in only 1 (5\%) patient (Table 8$)$.

\section{DISCUSSION}

The results of treatment of distal femoral fractures with the new internal fixator "LISS-DF" arising from clinical studies is presented here. LISS can be used in the treatment of all supra and intra-articular femoral fractures. The exception 


\begin{tabular}{|c|c|c|}
\hline & No. of cases & Percentage \\
\hline \multicolumn{3}{|l|}{ Knee- Flexion } \\
\hline less than $90^{\circ}$ & 14 & $70.00 \%$ \\
\hline $91^{0}-109^{\circ}$ & 5 & $25.00 \%$ \\
\hline $110^{\circ}$ & 1 & $5.00 \%$ \\
\hline \multicolumn{3}{|l|}{ Knee Extensor- Lag } \\
\hline $0-5^{0}$ & 11 & $55 \%$ \\
\hline $6^{0}-10^{0}$ & 8 & $40 \%$ \\
\hline$>10^{\circ}$ & 1 & $5 \%$ \\
\hline \multicolumn{3}{|l|}{ Limb Length Discrepancy } \\
\hline $0.5-1 \mathrm{cms}$ & 1 & $5 \%$ \\
\hline$>1 \mathrm{cms}$ & 2 & $10 \%$ \\
\hline \multicolumn{3}{|l|}{ Malalignment of more than $5^{0}$} \\
\hline Varus & 3 & $15 \%$ \\
\hline Valgus & 3 & $15 \%$ \\
\hline \multicolumn{3}{|l|}{ Functional Working Capacity } \\
\hline Same as before & 10 & $50 \%$ \\
\hline Same work but with some limitations & 5 & $25 \%$ \\
\hline Had to alter work & 4 & $20 \%$ \\
\hline Light Work only & 1 & $5 \%$ \\
\hline \multicolumn{3}{|l|}{ Complications } \\
\hline Superficial Infections & 2 & $10 \%$ \\
\hline Deep Infections & 2 & $10 \%$ \\
\hline Delayed Union & 0 & $00 \%$ \\
\hline Mal union & 0 & $00 \%$ \\
\hline Plate backout & 0 & $00 \%$ \\
\hline Implant Failure & 0 & $00 \%$ \\
\hline Stress Fracture & 0 & $00 \%$ \\
\hline \multicolumn{3}{|l|}{ Functional Results (Neer's score) } \\
\hline Good (70-85 units) & 13 & $65 \%$ \\
\hline Fair (55-69 units) & 6 & $30 \%$ \\
\hline Poor (below 55 units) & 1 & $5 \%$ \\
\hline
\end{tabular}

is the monocondylar fracture which is more practically treated using only screw osteosynthesis. ${ }^{12}$

In our study, of the 20 'lower end of femur'. 2 were Mullers type Al ,2 was Mullers type A2; 3 were Mullers type C1; 9 were Mullers type C2 and remaining 4 were Mullers type C3.In a study by Schutz M, Muller M et al Internal fixation using the LISS was performed at an average of 5 days (range: 0-29 days) after the injury. ${ }^{13}$ 48 fractures were operated on within the first 24 hours. Revision operations were required for 2 cases of implant breakage. 4 cases of implant loosening and 7 debridements to deal with infections. The study showed clearly that when working with LISS, primary cancellous bone grafting is not necessary. This is comparable to the results of recent, retrospectively evaluated study using the retrograde IM nailing'. The total follow up rate was $93 \% .5 \%$ non-union was observed.

In our study for fixation of fracture lower end femur, Ceftriaxone was administered intravenously before surgery and for 7 days after surgery and converted to oral antibiotics till suture removal. The average injury surgery interval was 4.25 days. 5 and 6 holed plates were used in $60 \%$ of patients.
Yeap EJ, and DeepakAS conducted a retrospective review on eleven patients who were treated for Type A and C distal femoral fractures (based on $\mathrm{AO}$ classification) between January 2004 and December 2004. All fractures were fixed with titanium distal femoral locking compression plate. The patient's ages ranged from 15 to 85 with a mean of 44. Clinical assessment was conducted at least 6 months post-operatively using the Schatzker score system. Results showed that four patients had excellent results, four good, two fair and one failure. ${ }^{14}$

Zlowodzki et alcombined these series $(n=-327)$ and evaluated the outcomes as part of a systematic literature review. Average nonunion, fixation failure, deep infection, and secondary surgery rates were $5.5 \%, 4.9 \%, 2.1 \%$, and $16.2 \%$ respectively. Some of the technical errors that have been reported for fixation failure have involved waiting too long to bone graft defects, allowing early weight bearing, and placing the plate too anterior on the femoral shaft. ${ }^{15}$

Locked implants are typically indicated in patients with osteoporosis, fractures with metaphyseal comminution where the medial cortex cannot be restored, or a short articular segment. Several case series have evaluated the use of locked implants in the treatment of distal femur fractures. The most commonly used implant in these case series has been the Less Invasive Stabilization System (LISS) with unicortical locking screws. ${ }^{16}$

Average flexion in this study was 104 degree with more than $50 \%$ patients having knee range of motion more than $110^{\circ}$. Average knee extensor lag in this study was 5.50 degrees. Out of 20 patients, in this study, very few patients had significant varus/ valgus malalignment. In a similar study by Vikranth PS et al the authors found that the average range of motion (flexion) was $110^{\circ}$ in $60 \%$ patients. In 4 patients average knee extension lag was not more than $4^{0}$. The range of motion in our study was found to be comparable to the study conducted by Vikranth PS et al. ${ }^{17}$

The duration of follow-up ranged from 3 months to 24 months. The average hospital stay for the patients in the present study was 20.3 days, in contrast to 31.5 days which were needed in patients treated by roller traction 69 and 44 days of hospitalization required following open reduction and plating and 63 days required for patients treated with alignment nailing.

Markmiller et al prospectively compared the outcomes of LISS and retrograde intramedullary nailing. At 12 months, no statistically significant differences were noted for nonunion, fixation failure, infection and secondary surgical procedures. However, this was a relatively small series and no power analysis was reported. ${ }^{18}$ 
Higgins et al compared the Locking Compression Plate, with distal locking screw fixation and bicortical locking and nonlocking diaphyseal fixation, to the angled blade plate in axial load to failure and cyclic axial loading in a cadaveric $1 \mathrm{~cm}$ fracture gap model. ${ }^{19}$ The locking construct had a significantly higher load to failure and less permanent deformation with cyclic loading. All of these studies reveal that locking plates with unicortical or bicortical diaphyseal fixation have adequate axial stiffness but more flexibility when compared to conventional fixed-angle implants. Although they have less torsional stiffness, the studies that evaluated torsional stiffness have shown that the distal fixation in locked implants is typically maintained while conventional fixed-angle implants have a higher rate of distal cutout from the fern oral condyles .Ricci et al compared axial stiffness, load to failure, and screw extraction torque for distal femoral locking plates with locked or nonlocked diaphyseal fixation in a non-osteoporotic and osteoporotic cadaveric supracondylar femur fracture gap model. Testing showed that locked diaphyseal fixation was only advantageous in the osteoporotic model. ${ }^{20}$

In our study, outcome in the form of regaining the lost knee function is assessed using NEER'S Score as shown below.In our study on 20 fractures around knee, 13 patients showed excellent result. Three patients showed good outcome ,3 patient showed fair outcome and 1 showed poor outcome. Similar outcome in patients with distal femoral fractures was also reported byKonuganti SR et al who reported excellent, good and fair results in $23.31 \%$, $54.11 \%$ and $22.58 \%$ cases respectively. ${ }^{21}$

\section{CONCLUSION}

Locking compression plate is a good fixation system for distal end femoral and proximal end tibia fractures, particularly intra-articular type and provides good angular stability by its triangular reconstruction principle. Early surgery as well as internal fixation by locking compression plate and early post-operative knee mobilization are essential for good union and good knee range of motion. Orthopaedic surgeons experience with locking compression plating technique will find the locking compression plate a useful technique, but requires attention to prevent complications.

\section{REFERENCES}

1. George A and Poduval M. Analysis of Limb Injury Patterns in Victims of Two Wheeler Accidents. Asian Journal of Medical Sciences. 2010; 1(1):14-15.

https://doi.org/10.3126/ajms.v1i1.2794

2. Lupescu O, Nagea M, Patru C, Vasilache CandPopescu GI. Treatment Options for Distal Femoral Fractures. Maedica (Buchar). 2015; 10(2):117-122.
3. O'Brien $\mathrm{CL}$, Menon $\mathrm{M}$ and Jomha NM. Controversies in the management of open fractures. Open Orthop J. 2014; 8:178-184. https://doi.org/10.2174/1874325001408010178

4. Meggitt BF, Juett DA and Smith JD. Cast-bracing for fractures of the femoral shaft. A biomechanical and clinical study. J Bone Joint Surg Br. 1981; 63-B (1):12-23.

https://doi.org/10.1302/0301-620X.63B1.7204465

5. Hoellwarth JS, Fourman MS, Crossett L, Goodman M, Siska P, Moloney GB, et al. Equivalent mortality and complication rates following periprosthetic distal femur fractures managed with either lateral locked plating or a distal femoral replacement. Injury.2018; 49(2):392-397.

https://doi.org/10.1016/j.injury.2017.11.040

6. von Keudell A, Shoji K, Nasr M, Lucas R, Dolan R and Weaver MJ. Treatment Options for Distal Femur Fractures. J Orthop Trauma. 2016;30 Suppl2: S25-S27.

https://doi.org/10.1097/BOT.0000000000000621

7. Kiran Kumar GN, Sharma G, Farooque K, Sharma V, Ratan R, Yadav S, et al. Locking Compression Plate in Distal Femoral Intra-Articular Fractures: Our Experience. Int Sch Res Notices. 2014;2014:372916.

https://doi.org/10.1155/2014/372916

8. Sain A, Sharma V, Farooque K, Muthukaran V and Pattabiraman K. Dual Plating of the Distal Femur: Indications and Surgical Techniques. Cureus. 2019; 11(12): e6483.

https://doi.org/10.7759/cureus.6483

9. Nayak RM, Koichade MR, Umre AN and Ingle MV. Minimally invasive plate osteosynthesis using a locking compression plate for distal femoral fractures. J OrthopSurg (Hong Kong). 2011;19(2):185-190.

https://doi.org/10.1177/230949901101900211

10. Gangavalli AK and Nwachuku CO. Management of Distal Femur Fractures in Adults: An Overview of Options. Orthop Clin North Am. 2016; 47(1):85-96.

https://doi.org/10.1016/j.ocl.2015.08.011

11. Schmidt-Rohlfing B, Pfeifer R, Kaneshige J, Hofman $M$, Knobe M, Sellei R, et al. Scoring systems for outcome after knee injuries. Injury. 2011; 42(3):271-275.

https://doi.org/10.1016/j.injury.2010.11.059

12. Schandelmaier P, Partenheimer A, Koenemann B, Grün $O A$ and Krettek C. Distal femoral fractures and LISS stabilization. Injury. 2001; 32 Suppl 3:SC55-SC63. https://doi.org/10.1016/S00201383(01)00184-X

13. Muller M, Aligoewer M, Schneider $\mathrm{R}$ and Willenegger $\mathrm{H}$. Manual der osteosynthese/ AO-Technik. 3rd edition. Berlin, Newyork: Springer Verlag, 1992

14. Yeap EJ and Deepak AS.Distal Femoral Locking Compression Plate Fixation in Distal Femoral Fractures: Early Results. Malaysian Orthopaedic Journal. 2007; 1 (1). pp. 12-17. ISSN 19852533 https://doi.org/10.5704/MOJ.0705.004

15. Zlowodzki M, Vogt D, Cole PAandKregor PJ. Plating of femoral shaft fractures: open reduction and internal fixation versus submuscular fixation. J Trauma. 2007;63(5):1061-1065. https://doi.org/10.1097/TA.0b013e318154c0b4

16. Marti A, Fankhauser C, Frenk A, Cordey J and Gasser B. Biomechanical evaluation of the less invasive stabilization system for the internal fixation of distal femur fractures. J Orthop Trauma. 2001; 15(7):482-487. https://doi.org/10.1097/00005131-200109000-00004

17. Markmiller M, Konrad $\mathrm{G}$ andSüdkamp N. Femur-LISS and distal femoral nail for fixation of distal femoral fractures: are there differences in outcome and complications? Clin Orthop Relat 
Res. 2004; (426):252-257.

https://doi.org/10.1097/01.blo.0000141935.86481.ba

18. Higgins TF, Pittman $\mathrm{G}$, Hines $\mathrm{J}$ andBachus $\mathrm{KN}$ Biomechanical analysis of distal femur fracture fixation: fixed-angle screw-plate construct versus condylar blade plate.J Orthop Trauma. 2007; 21(1):43-46.

https://doi.org/10.1097/BOT.0b013e31802bb372

19. Ricci W, Zheng Z, Jones B andCartner J. Does Locked Plating Provide Improved Fatigue Properties over Nonlocked Plating and Does Bone Quality Matter? OTA Annual Meeting Poster Presentation Boston, MA, 2007.
20. Konuganti SR, Jakinapally $S R$, Rao VP andRapur S. Management of distal femur fractures with locking compression plate: a prospective study. Int J Res Orthop. 2018; 4:208-213.

https://doi.org/10.18203/issn.2455-4510.IntJRes Orthop20180459

21. Vikranth PS, Chaitanya V and Vamshi VN. Management of distal femoral fractures treated with locking compression plate: a prospective study. Int J Res Orthop. 2019;5:478-484.

https://doi.org/10.18203/issn.2455-4510.IntJRes Orthop20191788

Author's Contribution:

AK - Concept and design of the study; interpreted the results, prepared first draft of manuscript and critical revision of the manuscript; SM - Statistically analysedand interpreted; reviewed the literature and manuscript preparation; $\mathbf{R} \mathbf{J}$ - Design of the study, statistically analysed and interpreted, preparation ofmanuscript and revision of the manuscript; SR - Concept and coordination of the overall study.

Work attributed to:

Department of Orthopedics, Bharati Vidyapeeth (Deemed to be University) Medical College and Hospital, Sangli, Maharashtra, India.

Orcid ID:

Dr.Abhijit Kadam - (i) https://orcid org/0000-0001-7741-9609

Dr.Sujay Mahadik - (1) https://orcid.org/0000-0002-9134-6423

Dr. Rahil Jiwani - (i) https://orcid.org/0000-0003-0816-7254

Source of Funding: None, Conflict of Interest: None. 